\title{
Religiosidade na adolescência: a necessidade de uma construção consciente e social
}

Religion in adolescence: the need for a conscious and social construction

\section{Débora do Nascimento Teófilo ${ }^{[a]}$, Sérgio Rogério Azevedo Junqueira ${ }^{[b]}$}

[a] Teóloga e Socióloga, Mestranda do Programa de Pós-Graduação em Teologia da Pontifícia Universidade Católica do Paraná (PUCPR), membro do Grupo de Pesquisa Educação e Religião (GPER), Curitiba, PR - Brasil, e-mail: deby.nteofilo@gmail.com

[b] Doutor em Ciências da Educação pela Universidade Pontifícia Salesiana (Roma-Itália), PósDoutor em Ciências da Religião pela Pontifícia Universidade Católica de São Paulo (USP), professor do Programa de Pós-Graduação em Teologia da Pontifícia Universidade Católica do Paraná (PUCPR), Curitiba, PR - Brasil, e-mail: srjunq@gmail.com

\section{Resumo}

O termo "adolescência" é essencial para definirmos um momento da vida humana socialmente, psicologicamente e religiosamente configurado, que interfere na construção da atuação individual e coletiva dos sujeitos. A composição desse conceito é a primeira etapa de um processo investigativo sobre o desenvolvimento religioso de adolescentes em situação de risco no contexto do município de Curitiba (PR). A exposição das referências desta pesquisa qualitativa, fundamentada em autores como Fowler (1992), Ávila (2003), Levisky (1998), Rassial (1997), Outeiral (2008), Erikson (1972) e 
Savage (2009), é essencial para compreendermos a inferência das questões religiosas na construção da identidade dos indivíduos.

Palavras-chave: Adolescência. Religião. Psicologia do desenvolvimento. Desenvolvimento religioso. Educação.

\section{Abstract}

The term "adolescence" is essential to define a moment in human life that is socially, psychologically and religiously configured. This moment interferes with the construction of individual and collective action of individuals. The composition of this concept is the first step of an investigative process on the religious development of adolescents at risk in the context of the city of Curitiba (PR). The exposure of references from this qualitative research, based on authors such as Fowler (1992), Avila (2003), Levinsky (1998), Rassial (1997), Outeiral (2008), Erikson (1972) and Savage (2009), is essential for understanding the implication of religious issues in the construction of the individuals' social identity.

Keywords: Adolescence. Religion. Developmental psychology. Religious development. Education.

\section{Introdução}

O presente artigo é a primeira fase de uma pesquisa realizada por pesquisadores do Grupo Educação e Religião (GPER) da Pontifícia Universidade Católica do Paraná (PUCPR) sobre o desenvolvimento religioso de adolescentes em situação de risco no contexto do município de Curitiba. No texto são apresentados os conceitos que irão subsidiar a análise da segunda etapa desse processo investigativo.

\section{A adolescência}

Inicialmente é necessário considerar o termo "adolescência" - ao compreendermos o trajeto histórico da civilização ocidental, percebe-se 
que as fases da vida humana são uma construção social, portanto esse período da vida deve ser compreendido a partir dos aspectos psicológicos, históricos e sociológicos. De acordo com o historiador Jon Savage (SAVAGE, 2009, p. 82), o termo "adolescência" foi usado pela primeira vez pelo psicólogo G. Stanley Hall em 1898, ao afirmar, com base nas ideias de Rousseau, que o "estado intermediário" entre a infância e a fase adulta não era determinado apenas pelas questões biológicas, mas também por questões sociais - "adolescência é mais que puberdade". Hall estabeleceu a fase entre os 14 e 24 anos como "adolescência", significando um tempo de "embriaguez mental e moral", portanto digno da "mais alta atenção científica”. A obra de G. S. Hall tem uma significação social, por formular propostas sociais e educacionais no trabalho com adolescentes.

Para G. S. Hall, o adolescente é aquele que está numa "condição volátil”, por ser "emocionalmente instável e fático". Com as emoções à flor da pele, é capaz de "estados psíquicos ardentes e fervorosos". O autor considera ainda que "o alvorecer da adolescência é marcado por uma especial conscientização do sexo" (SAVAGE, 2009, p. 87). Percebe-se que o trabalho de G. S. Hall tem uma significação social, uma vez que ele interpreta a adolescência sobretudo como uma construção social, considerando que os adolescentes são possuidores dos "sentimentos coletivistas" (GRINDER, 1968, p. 24).

Desse princípio também comunga Vitiello (1988, p. 8), ao afirmar a adolescência como um conceito sociológico, por ser determinado pelo grupo social por meio de "elementos sociogenéticos" como:

As leis trabalhistas que protegem e limitam o trabalho do menor, diferenciando as condições laborativas dos adolescentes das do adulto; o incremento de um sistema educacional democrático acessível à grande massa da população; o adiantamento do trabalho profissional pela crescente exigência de estágios probatórios e anos de formação escolar e técnica (VITIELLO, 1988, p. 11).

Daniel Becker (1986, p. 14-18), psicólogo, define a adolescência como "a passagem de uma atitude de simples espectador para outra, ativa, questionadora", que resultará em "revisão, autocrítica e transformação". O período de desenvolvimento da criança em adulto é marcado por 
mudanças corporais consideradas universais e por mudanças psicológicas, determinadas pelo ambiente e pelo meio cultural.

Segundo Outeiral (2005, p. 18), compreende-se a adolescência como uma etapa da vida, "um período evolutivo" em que o ser humano passa por "transformações biopsicossociais". O autor caracteriza a adolescência por elementos como

[...] a perda do corpo infantil; [...] a reorganização de novas estruturas e estado de mente; a aquisição de novos níveis operacionais de pensamento (concreto ao abstrato) e de novos níveis de comunicação (do não verbal ao verbal); a apropriação do novo corpo; o recrudescimento das fantasias edípicas; a vivência de uma nova etapa do processo de separação-individuação; a construção de novos vínculos com os pais, caracterizados por menor dependência e idealização; a primazia da zona erótica genital; a busca de um objeto amoroso; definição da escolha profissional (OUTEIRAL, 2005, p. 19).

A biologia faz uma diferenciação entre os termos "adolescência" e "puberdade". Considera o primeiro como uma "transição no desenvolvimento entre a infância e a idade adulta que envolve grandes mudanças físicas, cognitivas e psicossociais". O segundo é considerado como "um processo pelo qual uma pessoa alcança a maturidade sexual e a capacidade de reprodução". Considera-se que as transformações físicas biológicas marcam o fim da infância, produzindo um crescimento rápido ou "complexo processo de amadurecimento" do corpo. Portanto, a biologia considera que a "adolescência começa com a puberdade, processo que conduz à maturidade sexual ou fertilidade" (PAPALIA; OLDS, 2000, p. 440).

Para Osório (1992, p. 11), o termo puberdade (do latim pubertate sinal de pelos, barba, penugem), numa tendência universal, define as modificações biológicas; já adolescência (do latim adolescere - crescer) define as transformações psicossociais, e suas características estão ligadas ao ambiente sociocultural do indivíduo.

Ampliando um pouco mais a discussão da adolescência como uma construção social, marcada por um tempo da vida entre a infância e a idade adulta, Outeiral ressalta que em diferentes culturas e épocas, cada sociedade, ou ainda cada grupo social, lida com a adolescência de forma peculiar. A omissão ou a invisibilidade dessa fase da vida pode resultar 
na marginalização do indivíduo. Em alguns grupos sociais esse tempo da vida é marcado por rituais específicos carregados de linguagem simbólica (OUTEIRAL, 2005, p. 46-47).

\section{Formas de integração social na adolescência}

O rito de passagem ou de iniciação, em diferentes sociedades e culturas, tem a função de integrar o indivíduo ao grupo social. Outeiral diz que "participar do rito de iniciação, e assim se sentir integrado na cultura de seu grupo, poderá ser importante para o desenvolvimento normal do adolescente, não causando, necessariamente, dificuldades emocionais" (OUTEIRAL, 2005, p. 49).

Em um estudo sobre os aspectos de um rito de iniciação, Outeiral (2005, p. 46) descreve como exemplo o Brit Milah e o Bar Mitzvah, "ritos de passagem puberal” judaico. O primeiro é um rito de iniciação, quando o menino judeu é circuncidado aos oito dias do seu nascimento. O segundo é um rito de confirmação do primeiro, realizado quando o menino completa treze anos, sendo então introduzido no grupo de adultos.

$\mathrm{O}$ autor diz que os rituais devem ser considerados como "mecanismos sociais de defesa" que levam os adolescentes a aceitar as normas sociais, "renunciando as fantasias edípicas". É um "processo lento e doloroso em que o adolescente necessita realizar o luto pelo corpo e pela identidade infantil e pelos pais da infância". Nesse sentido, o Bar Mitzvah é uma representação da "aceitação, consciente e/ou inconsciente, das normas do clã e do Brit Milah (circuncisão), recrudescendo a ansiedade de castração e as ansiedades depressivas, paranóides e confusionais" (OUTEIRAL, 2005, p. 48).

Outro importante exemplo de integração social ou "mecanismos sociais de defesa" é o citado por Segalem (2002, p. 61) sobre as iniciações africanas, em que os chamados "noviços", após serem sujeitados a moratória sexual e alimentar, são encaminhados a "instrutores" que irão condicioná-los “à paciência e observância de um rigoroso código moral”, de acordo com o qual serão instruídos nos saberes da sua sociedade. São normas de comportamento que irão comprovar sua coragem e sua habilidade. Depois desse processo o novo status social é confirmado em uma 
grande festa popular, quando lhes é dado "um novo nome e depois são introduzidos a uma nova linguagem, ostentando escarificações e adereços".

Luiz Carlos Osório, ao ressaltar a importância de se demarcar o começo e o fim da adolescência, cita alguns ritos contemporâneos de iniciação, entre eles a Primeira Comunhão na Igreja Católica, a Profissão de Fé nas Igrejas Protestantes, o Bar Mitzvah dos judeus, o serviço militar, o baile de debutantes e o exame de vestibular das universidades, como possíveis formas de marcar o início da vida adulta (OSÓRIO, 1992, p. 51).

Jon Savage (2009, p. 35) conta que no início do século XIX, na Europa, a adolescência era marcada pela vida escolar que, apesar de estar centralizada na capela, tinha na instituição dos jogos de equipe a forma de marcar a passagem da adolescência. Era o "novo rito de passagem institucional" - os jogos podiam ser equiparados a ritos tribais pela severidade e brutalidade. O autor afirma que havia um ideal no processo de socialização em que se misturava a vida religiosa e o preparo físico e moral dos adolescentes.

Savage (2009, p. 88) afirma que G. S. Hall defendia a ideia de que o rito de passagem na sociedade industrial americana deveria ser marcado pelo processo de permanência na escola secundária, período que deveria ser prolongado e socialmente sancionado na "ampliação das oportunidades educacionais”. Para G. S. Hall, um prolongamento ou aumento do intervalo de moratória "seria mais um índice do grau de civilização", além de "oferecer um porto seguro para as insistentes demandas da sociedade industrial".

Segalem (2002, p. 47) comenta a opinião de alguns sociólogos da década de 1970, os quais afirmavam que "os ritos, e até as cerimônias, têm tendência a cair em desuso nas situações urbanas modernas em que a base material da vida, a fragmentação dos papéis e das atividades separam por si mesmas os papéis sociais". Para a autora, isso seria o mesmo que afirmar que a sociedade contemporânea não é capaz de "ações e pensamentos simbólicos". A autora reconhece que o que pode haver hoje é a "privatização dos ritos", ou seja, apagaram-se as marcas que tornavam o rito público; ela considera ainda que o que há hoje são formas mais modestas de celebração, o que significa que o rito foi reduzido a expressões mais simples, em função principalmente dos valores do individualismo. Para Segalem, o fato é que "todo ritual desmoronou quando a partilha da crença se rompeu", na sociedade contemporânea o "grupo reunido não é 
mais uma coletividade que participa de uma emoção comum" (SEGALEM, 2002, p. 58-61).

Merleau-Ponty (1961, p. 135), comentando a natureza da troca e da função simbólica nas obras de Mauss e Lévi-Strauss, diz que na sociedade mecanizada a troca (sociedade em ato) e a função simbólica "perdem sua rigidez e sua beleza hierática; a mitologia e o ritual são substituídos pela razão e pelo método, também por um uso inteiramente profano da vida, acompanhado, aliás, por pequenos mitos compensatórios sem profundidade".

Como mostra o texto já citado, numa linguagem simbólica os rituais de iniciação ou de passagem, em diferentes épocas e culturas, são formas de integrar o indivíduo ao grupo social, o que pode contribuir para apaziguar o sentimento de inadequação ou de exclusão próprios da adolescência. Como afirma Erikson (1972, p. 185), a "arregimentação ritual" pode contribuir para "assegurar o desenvolvimento no iniciado de um grau ótimo de obediência com um sentimento máximo de livre escolha e solidariedade". O autor comenta que cabe ao grupo social propor caminhos que proporcionem aos adolescentes condições de superar "as forças que os atraem para regressões infantis e descobrir processos de mobilização de sua força interior para atividades orientadas para o futuro" (ERIKSON, 1972, p. 180).

Considerando o fato da ausência de cerimônias e rituais públicos que marcariam o período de espera para a fase adulta, Erikson (1972, p. 188) afirma que a sociedade precisa estabelecer um vínculo ideológico com os adolescentes. O termo "ideologia" é usado no sentido mais vasto, de sistema de ideias ou de ideais de um grupo sem nenhuma conotação política contemporânea, como afirma o autor, o que poderá oferecer aos jovens possibilidades como:

(1) Uma perspectiva simplificada do futuro que abrange todo o tempo previsível e, assim, compensa a "confusão temporal" do indivíduo; (2) alguma correspondência fortemente sentida entre o mundo íntimo de ideais e perversidades e o mundo social com suas metas e perigos; (3) uma oportunidade para exibir alguma uniformidade de aparência e comportamento, neutralizando a consciência de identidade individual; (4) incentivos para uma experimentação coletiva com papéis e técnicas que ajudam a superar um sentimento de inibição e culpa pessoal; (5) introdução nos valores 
éticos da tecnologia predominante e, portanto, na competição sancionada e regulamentada; (6) uma imagem do mundo geográfico-histórico como quadro de referência para a identidade nascente do indivíduo jovem; (7) um fundamento lógico para um modo de vida sexual compatível com um sistema convincente de princípios; (8) submissão a líderes que, como figuras super-humanas ou "big brothers", estão acima da ambivalência da relação parental-filial (ERIKSON, 1972, p. 188).

Assim, Erikson (1972, p. 133, 157) chama a atenção para a importância de a sociedade estabelecer de forma institucionalizada o status e a função do adolescente, o que lhe poderá garantir um sentido de vida, pois o harmonizará com os valores do grupo. A ausência da moratória institucionalizada, ritualizada ou não, é que cria incentivos para o adolescente se filiar a formas organizadas de delinquência.

Em um conceito contemporâneo, Calligaris (2000, p. 18) afirma que a adolescência é hoje culturalmente idealizada como um "tempo particularmente feliz". Isso se mostra como uma contradição, pois o que na prática acontece é a privação de autonomia e a limitação no compartilhamento dos valores culturais. Mas tal contradição é própria da sociedade industrial, que, segundo Marcuse (1982, p. 26), cria falsas necessidades, ou seja, necessidades "super impostas aos indivíduos por interesses sociais particulares". Dessa forma, "perpetuam a labuta, a agressividade, a miséria e a injustiça”, pois são construídas sob a força do desejo, pela busca da felicidade individual, pela realização pessoal e pela satisfação emocional. Utilizam formas de capturar o desejo das pessoas, vendendo-lhes maneiras de pensar e sentir, morar e vestir. Para o autor, o que se consome não são apenas bens, mas, sobretudo, formas de vida. Para Calligaris (2000, p.78), há ainda a possibilidade da adolescência hoje ser um ideal dos adultos "como um tempo de férias permanentes, uma maneira de ser adulto quanto aos prazeres, mas sem as obrigações relativas". De acordo com o autor, isso deixa os adolescentes sem um referencial, uma vez que "os adolescentes pedem reconhecimento e encontram no âmago dos adultos um espelho para se contemplar. Pedem uma palavra para crescer e ganham um olhar que admira justamente o casulo que eles queriam deixar". 


\section{$\mathbf{0}$ desenvolvimento religioso na adolescência}

Para refletir sobre a religiosidade nessa fase da vida, é preciso ainda compreender o conceito de religiosidade como experiência religiosa, como uma forma do ser humano externar a sua busca pelo sagrado (ALVES, 2008, p. 13). É preciso considerar - com Ferraz (1965, p. 49) e Jung (1978, p. 11) - que o homem, por excelência, é um animal religioso (homo religiosus), e interpretar os valores religiosos como fundamentais no desenvolvimento cognitivo do ser humano nas diferentes fases da vida. É necessário entender a experiência religiosa como a capacidade humana de, além de provar, compreender ou "descobrir o sentido". De acordo com Croatto (2001, p.41), a experiência religiosa é uma experiência humana, portanto está condicionada pelo contexto histórico e cultural, além do "ser", peculiar a cada um. Assim, é uma experiência "vivencial relacional" com o mundo, com o Outro (transcendente) e com o grupo social.

Ávila (2003, p. 91) e Cipriani (2007, p. 144) explicam a experiência religiosa diferenciando-a em duas formas, ou em duas categorias. A primeira é denominada "religiosidade funcional", como sendo uma forma de experiência voltada para a busca de suprir necessidades próprias. Uma religiosidade motivada por busca de realização de desejos materiais e temporais. Portanto, uma religiosidade infantil e imatura, pobre de sentimento, pois possui caráter negativo de temor, de culpa e insegurança, em que a busca pelo transcendente é motivada por favores, pois se serve da divindade de forma utilitarista, "o que atende a uma mentalidade mágica". Isso se reflete num interesse maior pelo ritual do que pelo ético. Uma vez que o rito toma um caráter mágico de solução e de alívio, é um tipo de religiosidade "funcional" em que o indivíduo busca conhecer para estabelecer controle sobre a divindade, além de assumir da doutrina apenas o que convém, servindo-se da religião; caracteriza-se também por um comportamento religioso formal, de palavras não seguidas de práticas.

Outra forma de experiência religiosa apresentada pelos autores é denominada de "experiência de encontro", que resulta do encontro da pessoa com o Transcendente: "experiência pessoal" que tem seu cerne no estado místico da consciência. Esse tipo de experiência religiosa é primeiro individual e tem um caráter de mudança na pessoa, pois "toma 
vida dentro do peito de cada um". Tal experiência leva a um processo de maturação da consciência religiosa. Para os autores, a experiência que se dá na comunhão mística, no encontro com o "Totalmente Outro", pode ter uma capacidade de promover o amadurecimento do indivíduo ao lhe dar sentido. Ou seja, uma maturidade religiosa que se manifesta na busca por sentido e não na satisfação dos "instintos de sobrevivência". É uma experiência em busca de significado que conduz a pessoa à autotranscendência, a uma realidade inefável que chamamos Deus. O ser humano busca significado para sua existência na relação com Deus, com o próximo e com o mundo. Nessa experiência tem-se então uma visão articulada e harmônica da natureza, da sociedade e de si mesmo, que resulta em atitudes de caráter "heurístico", em valores coerentes com os próprios comportamentos, em "experiência cristalizada em atitudes", em integração e convivência com os outros. Em outras palavras, a experiência religiosa é concludente, se manifesta no viver e não na busca da satisfação de desejos ou necessidades materiais. Nesse aspecto, Jung (1978, p. 9-10) especifica a experiência religiosa como o resultado de uma atitude pessoal, de uma consciência transformada na experiência do "numinoso", termo usado por Otto (2007, p. 180) e que significa uma espécie de efeito dinâmico, independente da vontade, motivado pela fé, que leva à confiança e à lealdade na "potência" (ou transcendente) - a busca pelo sentido numa relação individual direta com o Sagrado.

Com base na teoria do desenvolvimento, Ferraz (1965, p. 52) afirma que é possível observar cronologicamente as mudanças na relação com o sagrado desde a infância até a adolescência. Ele descreve que as "primeiras noções de Deus" na infância são "assombrosamente concretas e animistas" - são o reflexo da imagem do Pai, ou seja, é a "paternalização da divindade". Aos 10 anos a criança percebe Deus como uma pessoa com quem pode se relacionar, aos 11 anos começa a discernir o que é efeito dos próprios atos e o que é ação de Deus, e o concebe como "espírito". Aos 12 anos a criança já é capaz de conjugar o espiritual com o material, e então é capaz de definir Deus como "metade homem, metade espírito". Aos 13 entra na fase em que vacila entre crença e descrença. Aos 14, se optou pela fé, tem uma percepção de Deus como "uma força que nos governa". Aos 15 é menos cética e concebe Deus como uma pessoa. Aos 16 tem dificuldade 
de expressar verbalmente sua fé, e considera Deus um mistério, não tendo ainda um conceito definitivo.

Ávila (2003, p. 159-162) afirma que "os adolescentes e os jovens são menos religiosos que os adultos". Em função do desenvolvimento do "pensamento abstrato", eles passam a ter um conceito de Deus mais "espiritual ou invisível”, como uma pessoa, alguém distinto. Porém, o adolescente não alcança uma relação pessoal com o Transcendente, apesar de já ter alcançado um desenvolvimento psicoafetivo. Para o autor, o que determina isso é o fato de não haver possibilidade de enfrentamento, o que "torna o processo de articulação pessoal mais lento". Outra possibilidade, segundo o autor, é a concepção infantil que alguns adolescentes têm de Deus. Ele afirma que

É mais freqüente uma concepção infantil de Deus entre aqueles que pertencem a famílias mais religiosas que entre a população em geral. [...] ao haver recebido uma educação religiosa com elementos mágicos, pueris e com conteúdos não pensados, mas decorados, o processo de amadurecimento atrasa, permanecendo por mais tempo resquícios de concepções infantis sobre Deus. [...] causa que explica fenômenos de reação e rejeição posteriores freqüentes em alguns ateísmos e agnosticismos próprios de muitos dos educados em colégios religiosos, famílias cristãs etc. (ÁVILA, 2003, p. 162).

Tanto para Cahn (1999, p. 143, 144) quanto para Ávila (2003, p. 163), a adolescência é um tempo marcado pela dúvida e diversificação de atitudes diante do religioso e por uma pluralidade de imagens e de conceitos de Deus, além dos conceitos religiosos como a "vida além da morte e o papel da Igreja”, o que dificulta a interiorização religiosa. É muito diferente da infância marcada pelo compartilhamento da crença da família, influenciada pela "educação recebida".

Ávila (2003, p. 165-169) afirma que os vestígios de "crítica e ruptura" dos adolescentes com as crenças começam em torno dos 11 anos, porém de forma "velada ou inconsciente", o que pode complicar "a articulação de um conceito adulto de Deus". São dúvidas que podem ter origem em fatores como: a integração entre conhecimento religioso e conhecimento 
científico e a integração entre a "vivência da Igreja e a ausência de Deus", no sentido afetivo e pessoal.

[...] Por que está tão distante? Por que o chamo e não responde? Para que chamar você se nunca senti sua presença? Essas poderiam ser algumas das perguntas que se faz ou que já nem sequer se faz o adolescente, porque a maioria deles não tem, ou pode ser que nunca tenham tido, essa experiência, mas apenas um conceito de Deus vazio de toda relação pessoal [...] (ÁVILA, 2003, p. 168).

$\mathrm{O}$ autor relata resultados de pesquisas realizadas em diferentes lugares do mundo, concluindo que o distanciamento dos adolescentes das crenças se dá em função da "frágil religiosidade familiar". Os que fazem um caminho contrário, ou seja, aqueles que mesmo sem uma influência familiar aderem às seitas ou aos novos movimentos religiosos, o fazem em busca de sentido para a vida ou em busca de soluções para problemas como doenças, drogas ou crise interna (ÁVILA, 2003, p. 174).

Para Oliveira (1963, p. 62), é necessário se dar continuidade no ensino da catequese iniciada na infância, levando em conta a capacidade dos adolescentes de associar conceitos doutrinários às situações concretas da vida, "apelando cada vez mais para o pensar" (como ato e capacidade). Para o autor, o ensino religioso deve "penetrar e esclarecer os momentos trágicos da vida familiar e social", e não "teimar em fechar os olhos à exigência de maior cultura". Ele afirma ainda que a comunhão solene não deve ser considerada como "um ponto máximo de cultura ou de formação", principalmente na adolescência, quando o jovem encontraria aconchego na igreja e "descobriria como a fé penetra na vida e como a vida é oração e serviço de Deus".

\section{O lugar da família e da instituição religiosa}

A religião no seio da família já não é mais determinada pelos pais. Inclusive está declarado no Artigo 16 do Estatuto da Criança e do Adolescente que o direito à liberdade, ao respeito e à dignidade compreende, entre outros, o direito à crença e culto religioso. Segundo Jacquet e 
Costa (2004, p. 228), na família contemporânea os valores estão "centrados na auto-realização e satisfação emocional”, e os relacionamentos familiares têm um sentido de "negociação aberta", inclusive a opção religiosa, resultando na pluralidade religiosa doméstica. Ou seja, a conversão de um membro da família a determinada religião não significa a adesão dos demais membros, inclusive dos filhos menores, o que pode gerar conflito ou não, dependendo da posição hierárquica do convertido no espaço familiar. Um fator que pode gerar o conflito familiar é o grau de engajamento do convertido na nova religião, como também da sua família na religião de origem. As religiões pentecostais têm um maior número de convertidos que vêm em busca de soluções para problemas e conflitos familiares são em sua grande maioria mulheres solteiras e casadas que tomam a iniciativa na esperança e busca de respostas.

De uma maneira geral, o pentecostalismo movimenta e chama a atenção de uma população feminina por conta da ênfase que dá à problemática da família. [...] o culto dedicado à família é um dos mais freqüentados por mulheres. Elas vão fielmente ao templo a fim de se engajarem e darem continuidade às correntes para exterminação do mal e de toda sorte de problemas domésticos, [...] com o marido e/ou com os filhos (JACQUET; COSTA, 2004, p. 62).

Porém, apesar do forte engajamento e comprometimento religioso da mulher, ela não leva consigo os filhos e o marido ou companheiro. $\mathrm{Na}$ maioria das vezes ela inicia uma caminhada solitária em busca de solução e respostas, financeiras e emocionais, para toda a família (JACQUET; COSTA, 2004, p. 62).

De modo geral, as instituições religiosas cristãs disponibilizam para a família o apoio e a orientação no magistério a fim de iluminar os fundamentos bíblicos e as motivações éticas, tornando o conhecimento acessível a todos. Propõe-se na sua "pedagogia eclesial suscitar convicções, oferecer ajuda concreta", orientar as famílias dentro da doutrina "em obediência a verdade que é Cristo", a cumprir seu ministério, sua missão. Oferece o ensino aos fiéis, por meio da "educação cristã", da catequese ou dos grupos de estudo. Fornece, desde a infância, uma compreensão total da existência e a integração, não só pela "doutrina, mas 
pelos gestos, sentimentos, emoções, esforços voluntários”. A formação religiosa institucional é uma formação de afetividade, que permite espaço para a formação da autonomia, integrando e absorvendo as experiências individuais (COMBLIN, 1962, p. 182-184; OLIVEIRA, 1963, p. 166-169).

A Igreja Católica, nos Documentos Conciliares, dá relevância à família, considerando-a a célula vital e primária da sociedade, o próprio fundamento da sociedade, a primeira escola das virtudes sociais, o ambiente natural e sobrenatural para a educação dos filhos, a primeira escola e estágio para o apostolado e a Igreja doméstica (JOÃO PAULO II, 1978, p. 41).

As Igrejas cristãs protestantes históricas estão baseadas na convicção de que a eclesiologia deve ser a origem da formação cristã. A educação cristã deve estar comprometida com o crescimento da vida eterna dentro da personalidade humana. Algumas denominações protestantes se organizam em pequenos grupos, outras na chamada "Escola Bíblica Dominical", porém na grande maioria o ensino está centralizado nos "cultos semanais". A Bíblia é o livro-texto, e a educação é "planejada para processar as Escrituras principalmente como conceitos que devem ser cridos e seguidos". O professor ou discipulador é membro da própria comunidade, comprometido com ela. Coloca-se como exemplo e modelo, "sujeito a autoridade de Deus através das Escrituras". O responsável pela formulação, elaboração ou planejamento da educação cristã é o líder, o Pastor. Em relação à formação das crianças, a família é considerada o centro do ensino e da formação cristã. Porém, não é a única - a Igreja tem a função de equipar ou preparar a família na sua tarefa de evangelização dos filhos, "lares cristãos onde meninos e meninas são criados no temor do Senhor" (RICHARDS, 1975, p. 245, 250).

James W. Fowler (1992, p. 17-21), psicólogo e teólogo americano, apresenta a partir de uma pesquisa empírica feita com pessoas de diferentes idades, camadas sociais e religião, a possível relação entre as etapas do desenvolvimento cognitivo humano e o desenvolvimento religioso. $\mathrm{O}$ autor se valeu dos conceitos formulados por Jean Piaget e por E. Erikson sobre a estrutura do desenvolvimento cognitivo humano, tomado no sentido dinâmico de impulsionar para uma evolução subsequente em direção à maturidade, e os relacionou ao desenvolvimento da fé, o que ele denominou de "estágios da fé", classificando-os em sete fases. Ele define fé como uma 
preocupação humana e universal, como "formas pelas quais ordenamos a vida", como sentido, valor e identidade, como "uma maneira pela qual uma pessoa ou grupo responde ao valor e poder transcendentes; fé no aspecto de serenidade, coragem, lealdade e serviço"; citando Smith o autor afirma que fé é "uma tranqüila confiança e alegria que capacita a pessoa a sentir-se em casa no universo, e a achar sentido no mundo e em sua própria vida, um sentido que seja profundo e último e que seja estável"; fé como uma forma de ver ou de conhecer o mundo. Entre as fases de desenvolvimento da fé marcadas pelo autor, interessa aqui a fase que corresponde à adolescência, a qual ele classifica de terceiro estágio, chamado de "fé sintético-convencional". Isso se dá quando a pessoa é capaz de sintetizar valores e crenças como forma de sustentar um sistema de ideias nos quais se baseia sua identidade, quando a pessoa amplia seu mundo para além da família. É a fase do pensamento operacional formal, quando a relação com Deus é estabelecida por meio de símbolos e rituais, imagens e valores.

A adolescência é uma fase em que o indivíduo poderá exigir uma relevância maior da religião por parte da família e da instituição religiosa, do contrário ele poderá abandoná-la ou substituí-la. Porém, se houver uma base firme no desenvolvimento religioso do adolescente, a religião poderá tornar-se um fator fundamental para auxiliá-lo na superação da crise adolescente e alcançar uma fé madura e estável.

\section{Considerações finais}

O que na sociedade contemporânea se configura como espaços para a articulação da construção da identidade, da inserção e da permanência do adolescente no grupo social? Não é fundamental o retrocesso a um modelo ritualizado de civilização, mas é de extrema importância e urgência que se reconheça que a adolescência é uma fase da vida que demanda recursos de inclusão social, uma medida de proteção, de amparo social e de acolhimento, dando assim a possibilidade de sonhar, idealizar e buscar um futuro, conferindo sentido à vida. Do contrário, os nossos adolescentes, cada vez mais cedo, buscarão respostas para a exclusão na violência e no crime, no qual eles são, facilmente e ritualisticamente, incluídos e valorizados. 
É possível perceber a importância da formação e do desenvolvimento da religiosidade nos adolescentes, bem como uma significativa perda na transmissão entre gerações na cultura contemporânea ocidental.

A perspectiva é que o estudo do desenvolvimento da religiosidade possa cooperar na identificação dos impactos da fé e nas características da experiência religiosa da sociedade atual.

Os autores convergiram nas características que definem os valores da nossa sociedade moderna como desagregadora, consumista, individualista, centrada na autorrealização e na valorização excessiva da satisfação emocional. O valor maior é dado ao presente; a velocidade das mudanças é tão intensa que não se tem noção de passado e nem esperança de futuro - o que resta é o vazio e a falta de sentido para a vida. As instituições religiosa e familiar têm refletido diretamente os resultados do ritmo do movimento da vida coletiva, bem como de seus valores. Assim também a sociedade tem refletido a desestruturação da família e da religião.

A religião foi reconhecida aqui como fornecedora de sentido à vida, como aquela que exerce um papel estabilizador, constitutivo e humanizador no existir humano. Porém, na prática ela tem sido interpretada pelas instituições sociais, inclusive a família, por um aspecto utilitarista e egoísta.

Ficou entendido que, se por um lado há no adolescente uma necessidade inata de pertença e de identificação, há na religião ou na religiosidade uma perspectiva vivencial relacional com o mundo, o transcendente e o grupo social, o que a possibilita conduzir o adolescente para uma experiência de encontro.

É fundamental resgatar, na sociedade desagregadora e descontinuada, bem como na família fragilizada e desestruturada, o sentido real da religião ou da experiência religiosa. Precisamos de um verdadeiro encontro com o Transcendente. Precisamos reconhecer que somos muito mais do que podemos ver e tocar. Mais certo do que o agora, existe o futuro e é nisso que precisamos transcender - é a vida que tem sentido a partir da esperança. Assim, reconhece-se que uma pesquisa de campo, por meio de uma observação participativa e de entrevista estruturada, a qual possibilitará uma aproximação com a realidade empírica, poderá resultar na ampliação desse trabalho. 


\section{Referências}

ALVES, R. 0 que é religião? São Paulo: Loyola, 2008.

ÁVILA, A. Para conhecer a psicologia da religião. São Paulo: Loyola, 2007.

BECKER, D. O que é adolescência? São Paulo: Brasiliense, 1986.

CALLIGARIS, C. A adolescência. São Paulo: Publifolha, 2000.

CAHN, R. $O$ adolescente na psicanálise: a aventura. Rio de Janeiro: Companhia de Freud, 1999.

CIPRIANI, R. Manual de sociologia da religião. São Paulo: Paulus, 2007.

COMBLIN, J. Educação e fé: os princípios da educação cristã. São Paulo: Herder, 1962.

CROATTO, J. S. As linguagens da experiência religiosa. São Paulo: Paulinas, 2001.

ERIKSON, E. H. Identidade, juventude e crise. Rio de Janeiro: Zahar, 1972.

FERRAZ, J. de S. Psicologia do adolescente. Limeira: Letras da Província, 1965.

FOWLER, J. W. Estágios da fé. São Leopoldo: Sinodal, 1992.

GRINDER, R. E.; STRICKLAND, C. E. A significação social da obra de G. S. Hall. In: BRITTO, S. de. Sociologia da juventude. Rio de Janeiro: Zahar, 1968. v. 1, p. 19.

JACQUET, C.; COSTA, L. F. Família em mudança. São Paulo: Cia Ilimitada, 2004.

JOÃO PAULO II. Sobre a função da família cristã no mundo de hoje. São Paulo: Loyola, 1978.

JUNG, C. G. Psicologia e religião. Petrópolis: Vozes, 1978.

LEVISKY, D. L. Adolescência: pelos caminhos da violência. São Paulo: Casa do Psicólogo, 1998. 
LEVISKY, D. L. Adolescência e violência: conseqüências da realidade brasileira. São Paulo: Casa do Psicólogo, 2000.

MARCUSE, H. A ideologia da sociedade industrial. 6. ed. Rio de Janeiro: Zahar, 1982.

MERLEU-PONTY, M. Signos. São Paulo: Martins Fontes, 1961.

OLIVEIRA, Z. de. O problema religioso na juventude. Lisboa: União Gráfica, 1963.

OSORIO, L. C. Adolescente hoje. Porto Alegre: Artmed, 1992.

OTTO, R. O sagrado. São Leopoldo: Sinodal; Petrópolis: Vozes, 2007.

OUTEIRAL, J. Adolescer: estudos sobre adolescência. Rio de Janeiro: Reviver, 2008.

OUTEIRAL, J. Clínica psicanalítica de crianças e adolescentes: desenvolvimento, psicopatologia e tratamento. 2. ed. Rio de Janeiro: Revinter, 2005.

PAPALIA, D. E.; OLDS, S. W. Desenvolvimento humano. 7. ed. Porto Alegre: Artes Médicas sul, 2000,

RASSIAL, J. J. A passagem adolescente: da família ao laço social. Porto Alegre: Artes e ofícios, 1997.

RICHARDSON, R. J. Pesquisa social. São Paulo: Atlas, 1985.

SAVAGE, J. A criação da juventude. Rio de Janeiro: Rocco, 2009.

SEGALEM, M. Ritos e rituais contemporâneos. Rio de Janeiro: FGV, 2002.

VITIELLO, N. Adolescência hoje. São Paulo: Roca, 1988.

Recebido: 17/12/2010

Received: 12/17/2010

Aprovado: 11/03/2011

Approved: 03/11/2011 